\title{
Environmental drivers of leaf phenology in trees of the tropical species Ficus obtusifolia
}

\section{Caín Ballestrini, Wilmer Tezara and Ana Herrera*}

\author{
Instituto de Biología Experimental, Universidad Central de Venezuela, Apartado 47114, Caracas, Venezuela. \\ *Corresponding author: ana.herrera@ciens.ucv.ve. Tel. +58 212 7510544; fax: +58 2127535897 \\ Received: 08 March 2011; Accepted: 19 July 2011
}

\begin{abstract}
Vegetative as well as reproductive phenology of tropical trees frequently occur synchronously at the end of the dry season. It has been repeatedly observed on two individuals of the tropical species Ficus obtusifolia growing in Caracas that they lose their entire foliage in a period of $48 \mathrm{~h}$ during the dry season and renew it within the next $72 \mathrm{~h}$. In order to gain knowledge on the mechanisms that govern leaf exchange in F. obtusifolia, we followed in these two individuals the seasonal changes in leaf and fruit phenology, water relations and environmental variables, and in another 25, phenology only. Although foliar exchange was always observed before the rainy season, it also occurred near the end of the rainy season. An increase in leaf turgor potential of mature leaves and a low sap flow velocity coincided with leaf fall. Foliar exchange in all 27 individuals, growing in locations with different elevation and, possibly, access to underground water, was bi-modal and occurred in a period of approximately one month around both equinoxes. The presence of fruits was also bi-modal, occurring after leaf renewal. The sequence of phenological events repeated itself in all the individuals studied, although with inter-annual and individual variations in date of foliar exchange. Leaf fall was independent of leaf water status and significantly correlated with, in decreasing order, day length, minimum air temperature, rainfall, maximum air temperature and total radiation. We conclude that in F. obtusifolia high nocturnal temperature, increasing daytime temperature and radiation, and low cloud cover apparently drove foliar exchange. Day length showed a strong correlation with leaf renewal possibly to due to the significant relationships between day length and environmental variables. Direct effects of day length alone were not evidenced, as foliar exchange took place during a long time-span around the equinoxes.
\end{abstract}

Key words: brevi-deciduous, day length, leaf fall, sap flow velocity, water relations

\section{INTRODUCTION}

Vegetative as well as reproductive phenology of tropical trees frequently occurs synchronously at the end of the dry season (Borchert, 1994a). Leaf age, water deficit and changes in day length (DL) have been related to the control of vegetative phenology and partially explain leaf abscission in tropical trees (Borchert et al., 2002; Munné-Bosch and Alegre, 2004). In tropical trees, phenological changes occur in a synchronous manner for relatively short periods during the equinoxes, independently of the seasonal rainfall pattern (Reich and Borchert, 1984). The long-term observation of many forest species in Costa Rica $\left(\mathrm{ca} .10^{\circ} \mathrm{N}\right)$ indicates that leaf fall and bud emergence take place during the driest and warmest part of the year, coinciding with the spring equinox (Borchert, 1994a; Borchert and Rivera, 2001).

Mean leaf flush dates in all 26 species of Ficus examined in Panamá fell within the first three months of the dry season; however, trees also flushed throughout the year (Windsor et al., 1989). In contrast, in trees of $F$. variegata growing in a seasonally wet tropical forest, leaf flushing was highly seasonal and correlated with rainfall; trees were annually deciduous, with a pronounced leaf drop and a pulse of new 
growth during the August-September drought (Spencer et al., 1996). These observations were interpreted as suggesting that leaf phenology is determined, rather than by seasonal changes in temperature and DL, by the annual rainfall and its seasonal distribution (Spencer et al., 1996).

Synchronicity in the foliar exchange of $F$. thonningii, $F$. citrifolia (Damstra et al., 1996) and $F$. variegata (Spencer et al., 1996) was interpreted, based on estimations of water status through rainfall values, as due to water deficit during the dry season. In contrast, Pereira et al. (2007) concluded that measured rainfall and estimated soil water storage probably did not accurately reflect the actual water status of trees of F. citrifolia, in which no relationship was found between the abovementioned variables and leaf exchange.

Efforts to understand the effect of seasonality on phenology in tropical climates have focused almost entirely on the rainfall pattern and/or DL, having ignored the effect of season on solar radiation (van Schaik et al., 1993). Although solar radiation is considered a limiting factor instead of an environmental signal that can synchronize phenological events due to great diurnal fluctuations in cloud cover (Renner, 2007), in trees of Hevea brasiliensis growing near the equator and in the subtropics, flowering was closely related to an increase in solar radiation within an annual cycle (Yeang, 2007). The hypothesis that $D L$ alone is the cue to phenology has been defended several times (e.g. Borchert et al., 2005; Borchert and Rivera, 2001) but more recently Calle et al. (2009) suggested that insolation near the autumn equinox, not $\mathrm{DL}$, is the driver of flower phenology.

Usually, it is not possible to separate the effect on leaf abscission of water deficit or DL under natural conditions, because abscission intensifies when water deficit increases and DL declines (Borchert et al., 2002). Nevertheless, in trees of different functional ecotypes, leaf exchange during an irregular drought caused by El Niño between June and August obeyed the regular pattern observed in non-El Niño years, suggesting that leaf fall is triggered by an unknown signal unrelated to the seasonal variation in plant water status (Borchert et al., 2002).

During the past 20 years, non-systematic observations in trees of Ficus obtusifolia Kunth (Moraceae), a native species (Berg and Simonis, 2000) growing in the Instituto de Biología Experimental (IBE), suggest that leaf fall occurs synchronously within individuals during March-April, near the spring equinox, followed by leaf flushing as early as $72 \mathrm{~h}$ after shedding, which indicates that this species is brevi-deciduous. This species is monoecious and individuals produce at least one fruit harvest per year. The synchronicity of leaf exchange in F. obtusifolia has two components of interest: first, it takes place during a short period, and second, it occurs between April and May after three or four months of drought.

Figs are an interesting group in that they are found in all tropical habitats, have exceptionally numerous congeners in almost any mainland tropical forest, and show intra-population intra-tree asynchronous flowering, yet strong individual synchronous flowering (Janzen, 1979). Flowering in figs should be synchronous within a tree, asynchronous between trees, random in the yearly cycle, and irregular from year to year (Damstra et al., 1996). Trees of $F$. thonningii growing in a watered, a non-watered and an intermediate habitat were all generally deciduous between April and August. Watered trees conformed to the general model, but half the trees in the seasonally dry habitat flowered synchronously in the cool dry season (Damstra et al., 1996).

The interplay between environmental variables and DL and their effect on leaf as well as flower phenology is a matter of controversy. In view of the abundant literature supporting or refuting the hypotheses of regulation of phenology by DL, water availability or radiation, we proposed to characterize the vegetative and reproductive phenology of $F$. obtusifolia and elucidate what environmental drivers influence leaf exchange in this species. In order to do this, we followed for three years the phenology, water relations, including turgor potential $\left(\psi_{\mathrm{T}}\right)$ and sap flow velocity ( $V$, as a measure of transpiration rate) of two trees growing in the gardens of the IBE and the phenology of 25 other individuals in nearby locations, and analyzed data in relation to environmental variables.

\section{MATERIALS AND METHODS}

Study area and plant material: The study area, located in Caracas ( $10^{\circ} 30^{\prime} \mathrm{N}-66^{\circ} 55^{\prime} \mathrm{W}$ ) and of approximately $10 \mathrm{~km}^{2}$, included eight locations at elevations of 865 (two locations), 868 (two), 888 (one), 1,005 (two, including IBE) and $1,030 \mathrm{~m}$ (one). At the lower elevations, the water table was possibly higher due to the proximity of the Guaire river and/or garden hosing during the dry season; at the highest 
locations, which included the gardens of IBE, trees were not hose-watered. Trees were between 5- and 20-m-high. The trees examined in one of the lower locations were planted, whereas the rest most probably grew from naturally dispersed seeds. Phenological and physiological measurements began during the dry season before the estimated leaf fall date and continued until the end of the year. Rainfall, air temperature (T) and total radiation (TR) data were collected by a weather station mod. Vantage Pro (Davies Instruments, Hayward, CA, USA) at IBE. Rainfall data were also obtained from the weather station in the main campus of Universidad Central de

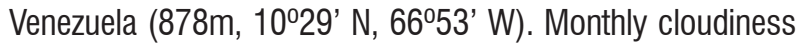
was estimated as the frequency of days with integrated TR 70 $\%$ or higher than the yearly maximum.

Phenology: During 2003, 2004 and 2006, quantitative weekly records were made of the number of young and mature leaves and fruits in branches ( $n=10$, five branches per tree) labelled $1 \mathrm{~m}$ from the distal end in the two trees growing in IBE. In the other 25 trees growing in the other locations, qualitative weekly records were taken in 2006 of the presence of fruits and of young and mature leaves, assigning the following values to leaf age: 0 , leafless; 1 , young leaves; 2 , mature leaves; 3 , mixture of different-aged leaves and 4 , senescent leaves.

Water relations: Leaf water potential of the two trees at IBE was measured at dawn in disks of different leaves $(n=6)$ placed in C52 chambers connected to an HR33T microvoltmeter operated in the dew point mode (Wescor Inc., Logan, UT). Osmotic potential was measured in the same manner after freezing the disks in liquid nitrogen. The $\psi_{\mathrm{T}}$ was calculated as the difference between water and osmotic potential. Sap flow velocity in the two trees at IBE was measured during 2004 and 2006 as previously described (Herrera et al., 2008) with thermal dissipation probes mod. TDP-30 (30$\mathrm{mm}$ long) connected to a DL2e data logger (Dynamax Inc., Houston, TX, USA). Five sensors were inserted in the main trunk of each tree at approximately $2 \mathrm{~m}$ from the ground. For access reasons, all sensors faced SW. Voltage was adjusted to give an average maximum temperature difference between the heated, downstream part of the sensor and the reference, upstream thermocouple of approximately $8^{\circ} \mathrm{C}$. Maximum $\mathrm{V}$ was calculated as the maximum value for each sensor on a given date $(n=5)$.
Statistics: Values are mean \pm SE. Correlations were done using the Oriana 3 and the Sigmaplot $7.0(p<0.001)$ packages. Dates (day of year) were converted into angles to draw the circular diagrams of leaf fall and presence of fruits using the Oriana 3 package.

\section{RESULTS}

During the years of study monthly courses of maximum TR $\left(\mathrm{TR}_{\max }\right)$, maximum and minimum $\mathrm{T}\left(\mathrm{T}_{\max }\right.$ and $\mathrm{T}_{\min }$, respectively), their difference $(\Delta T)$ and minimum relative humidity $\left(\mathrm{RH}_{\text {min }}\right)$ were similar and marked changes were observed in all variables near the equinoxes (Figure 1). Also shown are values of TR calculated after Jones (1983) considering the angle of incidence of the sun and the latitude of Caracas. Incident TR on clear days is $98-100 \%$ of the yearly maximum between March and September; nevertheless, $\mathrm{TR}_{\text {max }}$ was significantly closer to the calculated monthly maximum in March and September than in June and July, which coincided with the lowest estimated cloudiness in March and September (Figure 1).

Figure 2 shows the seasonal changes in leaf phenology, water relations of trees and rainfall at IBE. Trees showed a first peak of foliar exchange between April and May 2003 and 2004, and between May and July 2006, when both age classes coexisted, and a second peak between October and November 2004 and 2006; in November 2003, only 50 \% of leaves were shed. Leaf exchange occurred both before the beginning and towards the end of the rainy season, with the exception of exchange in July 2006. Flushing without significant shedding occurred in May 2006 and coincided with fruiting. Leaf exchange took place in five out of six events between 3 and 43 days after the equinoxes. Fruits appeared in 2003 and 2004 two and 2.5 months after shedding, respectively, at the beginning of, but not during the rainy season; fruit production not related to foliar exchange was observed in April 2006.

The $\psi_{\mathrm{T}}$ of mature leaves measured around the dates of foliar exchange was higher just before leaf shedding than before (Figure 2). In young leaves $\psi_{\mathrm{T}}$ increased with time (2003), was lower than in mature leaves (2004) or was similar to that of mature leaves (2006). Sap flow rate was low before leaf shedding and, at the beginning of rains, it increased 5.5, 1.5 and 11 times in 2003, 2004 and 2006, respectively (Figure 2). 


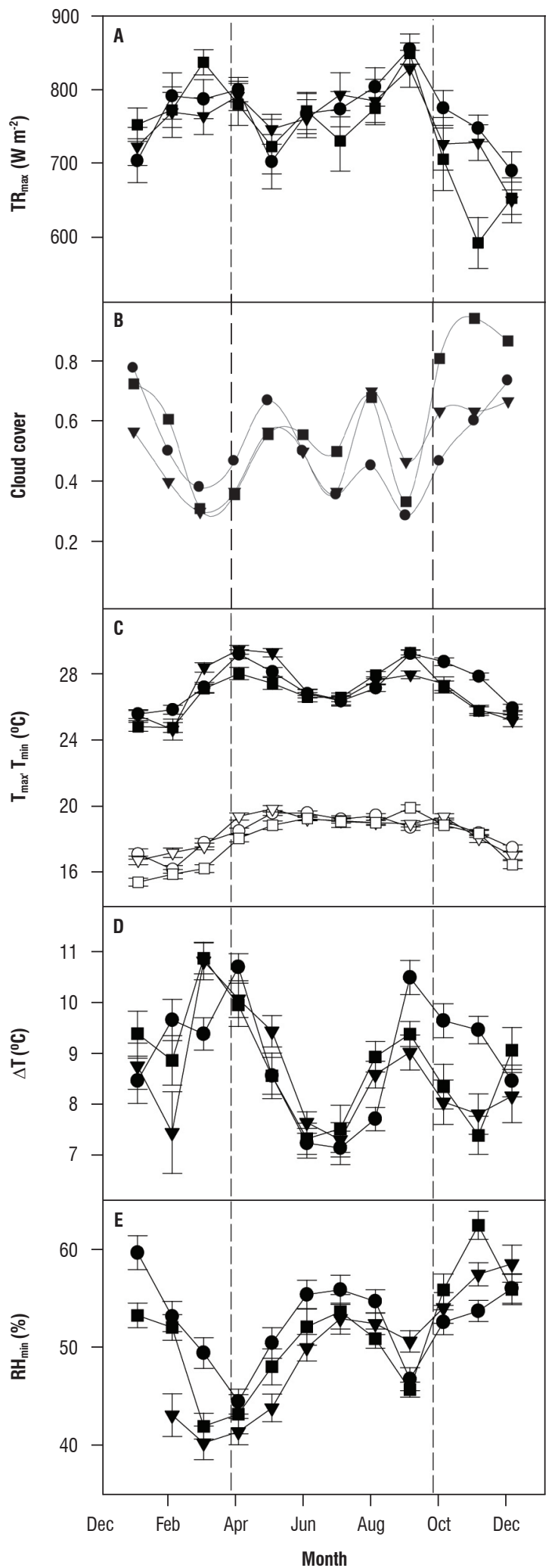

Figure 1. Monthly changes in: A, calculated (no symbols) and measured (symbols) maximum total radiation; B, estimated cloud cover; C, maximum (closed symbols) and minimum (open symbols) air temperature; D, their difference and E, minimum relative humidity for 2003 (triangles), 2004 (squares) and 2006 (circles). Values are mean $\pm S E(n=30)$. The vertical broken lines indicate the equinoxes. 


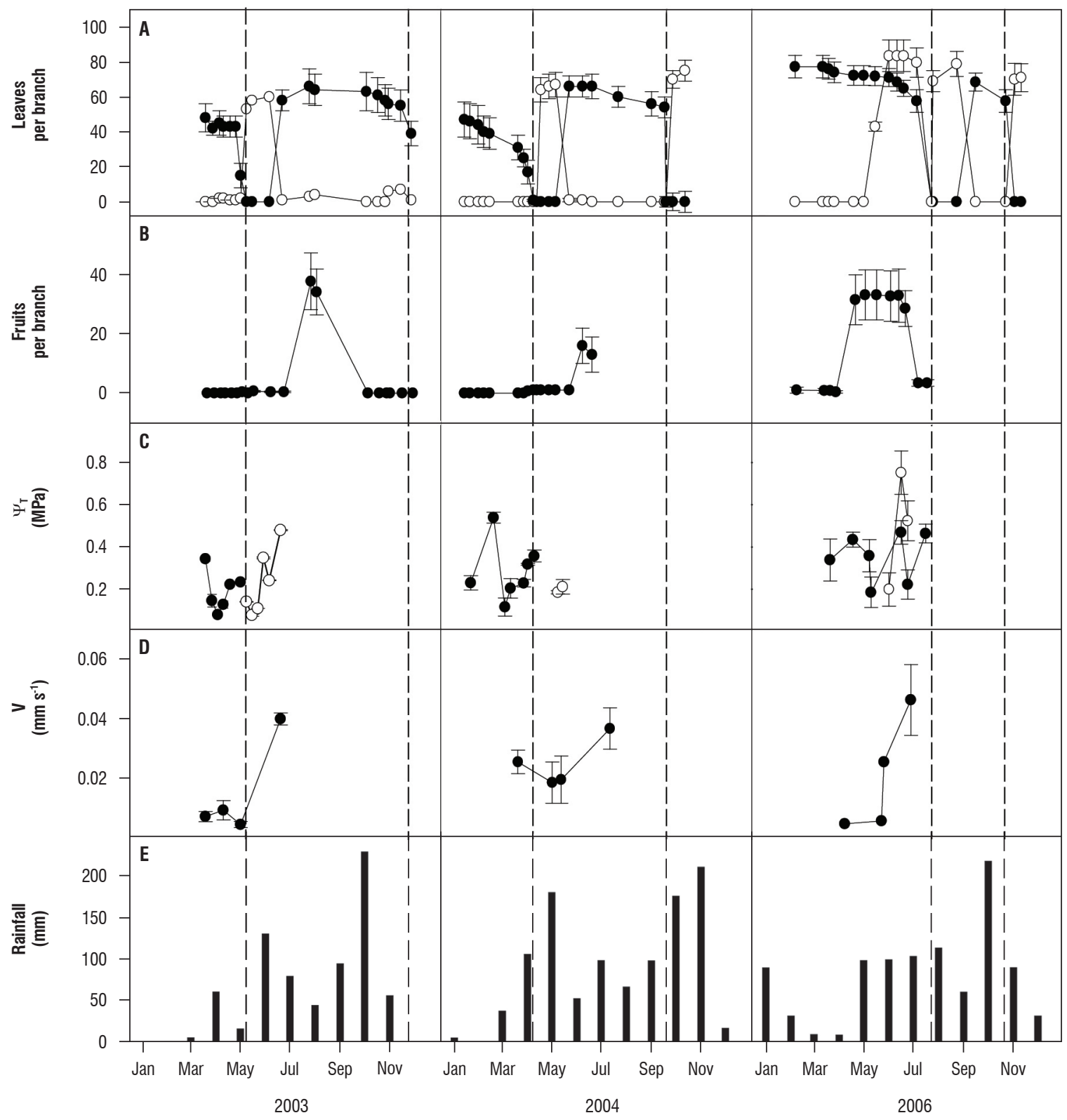

Figure 2. Seasonal changes in leaves of plants of Ficus obtusifolia growing in the gardens in: (A), number of mature (closed circles) and young (open circles) leaves per labelled branch; (B), number of fruits per branch; (C), turgor potential of mature (closed circles) and young (open circles) leaves; (D), maximum sap flow velocity, and $(E)$, monthly rainfall. Values are mean $\pm S E(n=10$, five branches per two trees, $(A, B) ; n=6$, three leaves per two trees, $(C)$; and $n=6$, three sensors in two trees, (D). Broken vertical lines serve as guides for time of leaf fall. 
In the whole study area, shedding was concentrated between March and April and between September and October 2006; based on the presence of young leaves alone, exchange apparently occurred from April to May and from September to October (Figure 3). Peaks of fruit production were observed in February, August and October (Figure 3).

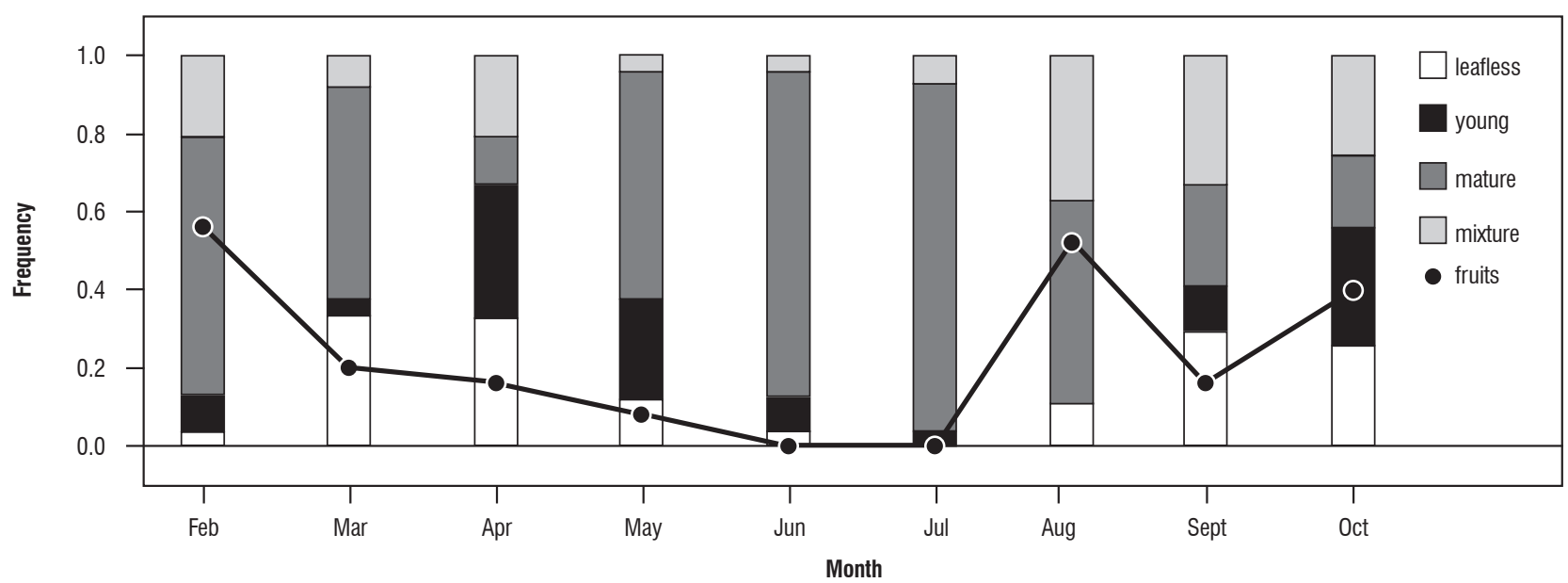

Figure 3. Seasonal changes in Ficus obtusifolia in the frequency of trees bearing no leaves (open bars), young leaves (closed bars), mature leaves (hatched bars) and a mixture of young and mature leaves(cross-hatched bars), and fruit-bearing trees (circles). Symbols as indicated. ( $\mathrm{n}=27$ trees).

When dates of leaf fall and presence of fruits for all 27 trees were converted to angles and a circular analysis was performed, clearly bi-modal distributions were found (Figure 4).

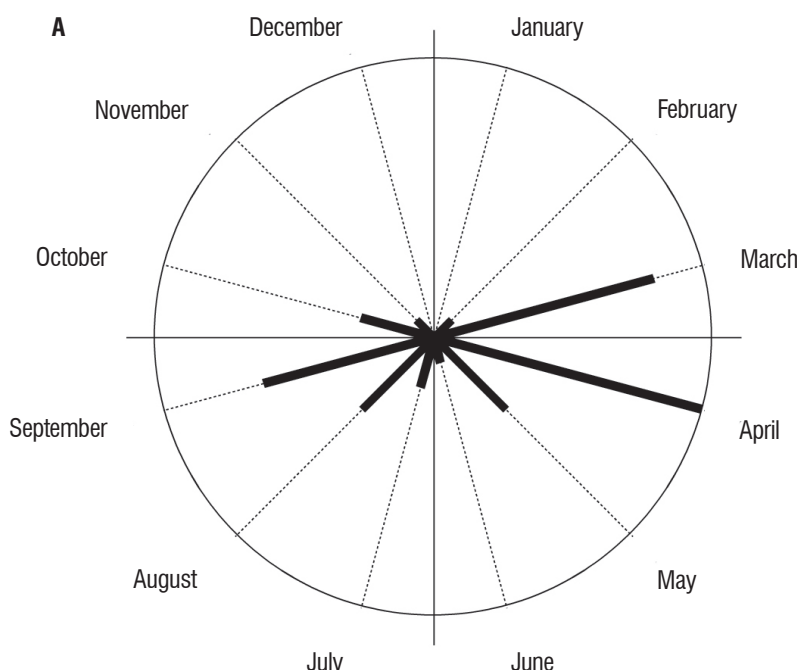

The environmental variables examined during the three years of study showed high correlations with $\mathrm{DL}$, all but $\mathrm{T}_{\min }$ having marked changes at the equinoxes; values of $\mathrm{T}_{\text {min }}$ lay on a plateau between equinoxes (Figure 5).

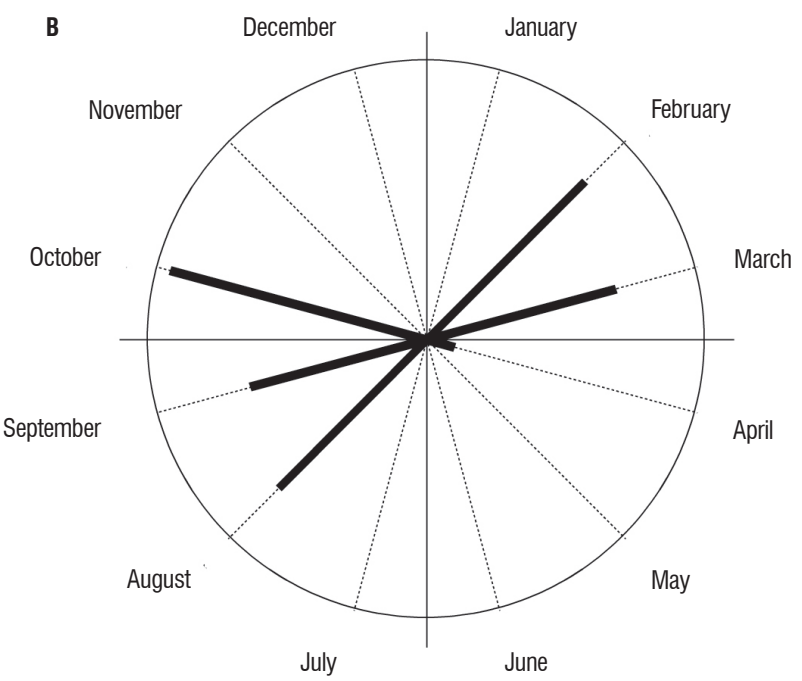

Figure 4. Dates in 27 trees of Ficus obtusifolia growing in Caracas for: (A), leaf shedding, and (B), presence of fruits. 


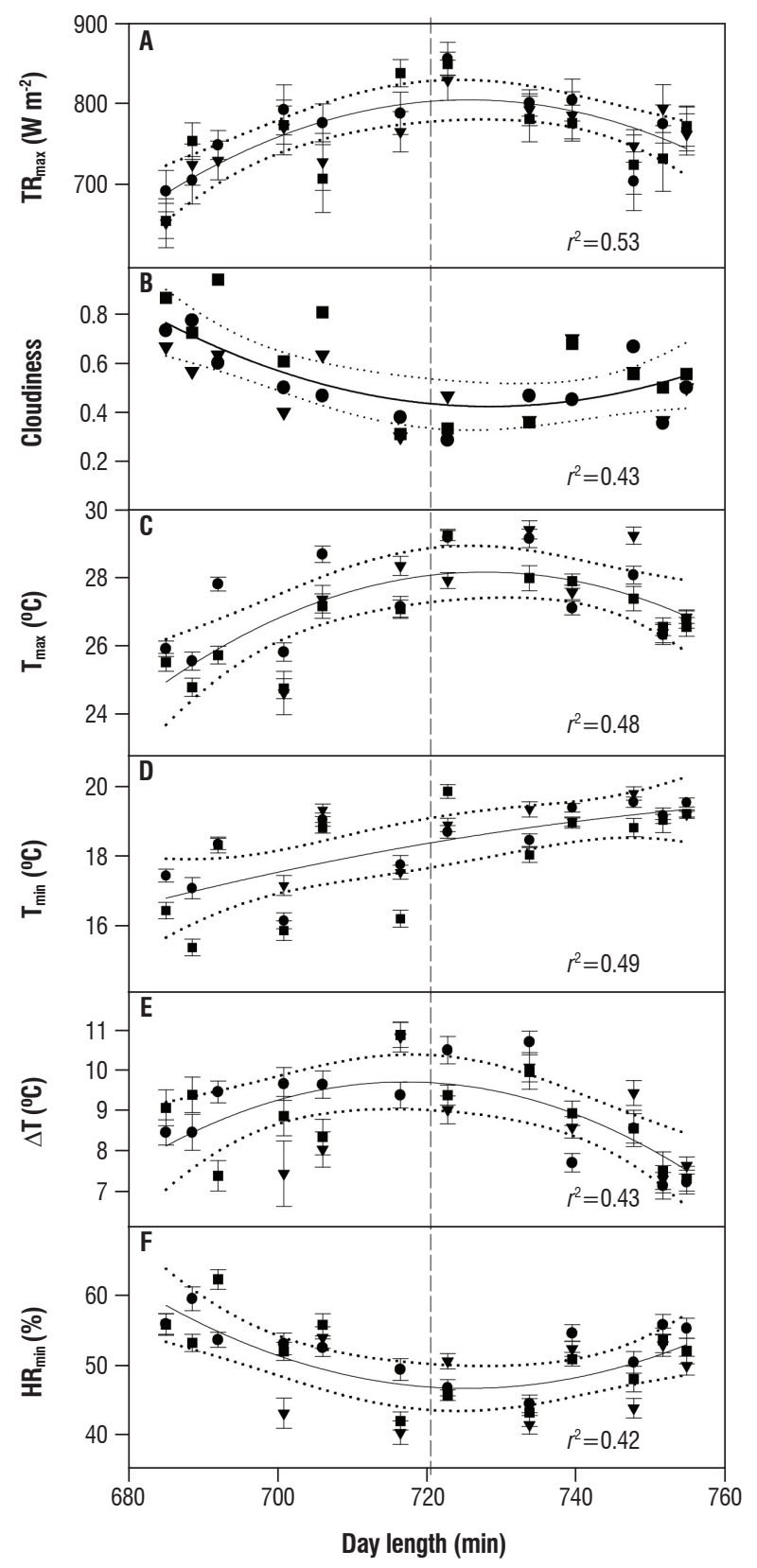

Figure 5. Changes with day length in: (a), maximum total radiation; (b), cloudiness; (c), maximum air temperature; (d), minimum air temperature; (e), temperature difference, and (f), minimum relative humidity, for 2003 (triangles), 2004 (squares) and 2006 (circles). Values are mean \pm SE $(n=30$ days of the month), except for cloudiness, where values are means. The regression line (solid), $99 \%$ confidence intervals (dotted lines) and determination coefficients $(p<0.05)$ are shown. The vertical broken line indicates the equinoxes.

Circular-linear correlations between leaf fall and environmental variables done using Kuiper's test were highly significant for all variables (Table 1).
Table 1. Circular-linear correlations between date of leaf shedding and environmental variables, including rainfall during the previous month, done using Kuiper's test. Values of $r$ and $P$ are indicated.

\begin{tabular}{ccc}
\hline Variable & $\boldsymbol{r}$ & $\boldsymbol{P}$ \\
\hline $\mathrm{DL}$ & 0.91 & 0 \\
$\mathrm{~T}_{\min }$ & 0.87 & 0 \\
Rainfall & 0.6 & 0 \\
$\mathrm{~T}_{\max }$ & 0.49 & 0 \\
$\mathrm{DT}$ & 0.42 & 0 \\
$\mathrm{TR}_{\max }$ & 0.42 & 0 \\
$\mathrm{RH}_{\min }$ & 0.31 & 0.01 \\
\hline
\end{tabular}

Complete leaf shedding took place at critical values of all variables, except for $\mathrm{DL}$, for which shedding occurred after the equinoxes (Table 2).

Table 2. Mean values of day length, minimum and maximum air temperature, temperature difference, maximum total radiation, and minimum relative humidity on dates with closed canopy and at complete shedding.

\begin{tabular}{ccc}
\hline Variable & closed canopy & complete shedding \\
\hline $\mathrm{DL}(\mathrm{min})$ & $710 \pm 6$ & $740 \pm 6^{*}$ \\
$\mathrm{~T}_{\min }\left({ }^{\circ} \mathrm{C}\right)$ & $17.8 \pm 0.3$ & $18.7 \pm 0.1^{\star}$ \\
$\mathrm{T}_{\max }\left({ }^{\circ} \mathrm{C}\right)$ & $25.4 \pm 0.2$ & $27.1 \pm 0.0^{\star \star}$ \\
$\mathrm{DT}\left({ }^{\circ} \mathrm{C}\right)$ & $9.8 \pm 0.2$ & $10.6 \pm 0.1^{*}$ \\
$\mathrm{TR}_{\text {max }}\left(\mathrm{W} \mathrm{m}{ }^{-2}\right)$ & $732 \pm 8$ & $799 \pm 3^{\star \star}$ \\
$\mathrm{RH}_{\min }(\%)$ & $57 \pm 1$ & $50 \pm 0^{\star *}$ \\
\hline
\end{tabular}

Values are mean \pm SE $(n=11)$. Significance after a one-way ANOVA comparing values at closed canopy and at shedding is indicated as *, $P<$ $0.03 ;{ }^{* *}, P<0.01$.

\section{DISCUSSION}

Pattern of leaf and flower/fruit phenology: The individuals of Ficus obtusifolia showed a brevi-deciduous behaviour, one of the four functional ecotypes identified in tropical forests based on vegetative phenology (details in Borchert, 1994a). This behaviour was observed in the entire study area, leaf fall being generally massive, and flushing almost immediate and synchronous in each tree, in spite of possible differences in soil water availability (season, watertable height and irrigation) and, in the case of the individuals at IBE, at a high leaf water status. No synchronicity among individuals was observed, although foliar exchange occurred in all trees at approximately the same time of the year.

The bi-modal vegetative phenology in F. obtusifolia in our study site resembles that in $F$. racemosa in southwest Asia 
$\left(21^{\circ} \mathrm{N}\right)$, in which leaf exchange occurred during both the dry and the rainy season (Zhang et al., 2006). In contrast, a marked pattern of foliar exchange in $F$. obtusifolia was not found in Barro Colorado Island (Milton, 1991). Our results coincide with Milton's (1991), in that leaf fall occurred massively. Mean leaf flush dates in all 26 species of Ficus examined in Panamá fell within the first three months of the dry season; however, trees also flushed throughout the year (Windsor et al., 1989), coinciding with the flushing recorded by us in May 2006. Similarly, in trees of $F$. obtusifolia (this study) and $F$. citrifolia (Pereira et al., 2007) leaf flushing sometimes overlapped leaf shedding.

Flushing without shedding during May 2006 in $F$. obtusifolia was unexpected and related to earlier fruiting with a denser canopy. Inter-annual differences in rainfall accumulated up to May do not help explain inter-annual phenological differences, since rainfall was similar between 2004 and 2006 and much higher than in 2003 (an El Niño, drier year). Rather, our phenological observations support those that indicate that flushing and flowering are synchronous in an individual fig but asynchronous in populations (Janzen, 1976; Damstra et al., 1996).

Foliar exchange in F. obtusifolia during the rainy season had not been observed by us before; it may have passed unnoticed before this study or else was due to inter-annual changes in rainfall. Anomalies in tree performance with respect to the hypothesis of Calles et al. (2009) that trees sense daily TR can be explained by regular climatic events, such as seasonality of rains (Lüttge and Hertel, 2009). In the present study, rainfall up to April was in 20061.4 times that in 2003 or 2004 . The high correlation observed by us between shedding and rainfall is intriguing, since leaves fell during both the dry and the rainy season. Shedding occurred at times with lowest cloud cover, which allowed the occurrence of the highest yearly $\mathrm{TR}_{\max }$.

In F. thonningii, F. citrifolia (Damstra et al., 1996) and F. variegata (Spencer et al., 1996), synchronicity in the foliar exchange was attributed to water deficit during the dry season. In contrast, Pereira et al. (2007) did not find any relationship in trees of $F$. citrifolia between measured rainfall, or estimated soil water storage, and leaf exchange.

Fruits were produced in F. obtusifolia twice a year, when the canopy was constituted mostly by mature leaves. Such synchronicity and bi-modality in fruit production was also observed in $F$. variegata, which is also a monoecious species. In F. racemosa, another monoecious species, on the contrary, fruits were produced asynchronously and this was interpreted as an adaptive trait to avoid self-fertilization (Zhang et al., 2006).

Water relations and foliar exchange: Neither drought nor low leaf water status were apparently requisites for leaf shedding, since leaves fell during both the dry and the rainy season, and at a high $\psi_{T}$ during the dry season. The increase in $\psi_{\mathrm{T}}$ observed in mature leaves before shedding could have been due to the water conservation exerted through low transpiration rates, suggested by low $V$. Increases in $\psi_{\mathrm{T}}$ as well as $V$ observed after foliar exchange were evidently a consequence of rains. In deciduous species, water potential measured under drought remained close to or above the values of the rainy season due to the joint diminution of stomatal conductance and total leaf area, which revealed a poor or null relation between leaf fall and water status (Choat et al., 2006).

The independence of foliar exchange from water status in F. obtusifolia occurred as previously reported for brevideciduous species, in which new leaves expand using water stored in the trunk and branches that re-hydrate due to the reduction in transpirational water loss brought about by shedding (Borchert, 1994b). Leaf exchange in trees of different functional types in a seasonally dry forest was independent from xylem water potential, regardless of proximity to a readily accessible water source (Valdez-Hernández et al., 2008).

Environmental variables and foliar exchange: Shedding occurred around the equinoxes when $\mathrm{TR}_{\max }, \mathrm{T}_{\max }$ and $\Delta T$ increased. The $D L$ and the angle of incidence on the Earth surface determine the amount of solar radiation reaching the atmosphere (Jones, 1988) and therefore air temperature, but cloud cover related to rainfall also affects measured incident TR. The effects of annual changes in TR and DL are concurrent and additive. In F. citrifolia at $23^{\circ} \mathrm{S}$, leaf shedding occurred during the dry season after the autumn equinox at the lower $T_{\max }$ and $T_{\min }$ (Pereira et al., 2007) when TR was half the value at closed canopy (TR obtained as indicated in Calles et al., 2009), suggesting a correlation between shedding and declining TR. In contrast, flushing events in Enterolobium cyclocarpum at $10^{\circ} \mathrm{N}$ were highly correlated with higher dryseason temperature (Rojas-Jiménez et al., 2007). 
Leaf exchange in F. obtusifolia took place after the equinoxes but the time-span was on occasions too long to enable the conclusion that there was a direct effect of $D L$ on leaf phenology. The effect of $\mathrm{DL}$ on shedding observed by us in F. obtusifolia and by Yeang (2007) in H. brasiliensis around the equinoxes does not necessarily imply photomorphogenic effects of DL on phenology; near the equator, total TR received or the ability to sense daily changes in TR are essential for annual rhythms and may operate in a way independent from circadian clocks entrained by the phytochrome (Lüttge and Hertel, 2009). Flowering in $H$. brasiliensis near the equinoxes was attributed to high insolation (Yeang, 2007); in contrast, in two tropical tree species growing between 4 and $28^{\circ} \mathrm{N}$, flowering, which occurred twice a year, coincided with declining insolation (Calle et al., 2009). Controlled experiments in F. obtusifolia varying TR and DL could help clarify the possible photoperiodic control of leaf phenology in this species.

In the present study, TR was actually measured, in contrast to the above studies (Yeang, 2007; Calle et al., 2009), allowing for a more direct estimation of its effect on leaf phenology. In addition, since values of TR, rainfall and $\mathrm{RH}$ were available, we were able to find a relationship between leaf exchange and rainfall through its relation with cloud cover.

\section{CONCLUSIONS}

Leaf phenology in trees of $F$. obtusifolia was bi-modal, with peaks of foliar exchange occurring during both the dry and the rainy season. The sequence of phenological events was repeated in all the individuals studied, although with interannual and individual variations in date of foliar exchange. In F. obtusifolia high nocturnal temperature, increasing daytime temperature and radiation, and low cloud cover apparently drove foliar exchange. Day length showed a strong correlation with leaf renewal possibly due to its significant relationships with environmental variables. Direct effects of $\mathrm{DL}$ alone were not evidenced, as foliar exchange took place during a long time-span around the equinoxes.

Acknowledgements: This work was partly funded by grants FONACIT S1-200000023 and CDCH 03.00.6524.2006 (Venezuela). Rainfall data from the Ciudad Universitaria weather station were provided by Judith Hernández, Ingeniería Hidrometeorológica, Facultad de Ingeniería, Universidad
Central de Venezuela. Air temperature, rainfall and total radiation data were provided by the Arboretum Experimental Station, Instituto de Biología Experimental.

\section{REFERENCES}

Berg CC, Simonis JE (2000) Moraceae y Cecropiaceae. Flora de Venezuela. Fundación Instituto Botánico de Venezuela "Dr. Tobías Lasser", Caracas.

Borchert R (1994a). Water status and development of tropical trees during seasonal drought. Trees 8:115-125.

Borchert R (1994b) Soil and stem water storage determine phenology and distribution of tropical dry forest trees. Ecology 75:1437-1449.

Borchert R (1998) Responses of tropical trees to rainfall seasonality and its long-term changes. Climat. Change 39:381-393.

Borchert R, Rivera G (2001) Photoperiodic control of seasonal development and dormancy in tropical stem succulent trees. Tree Physiol. 21:213-221.

Borchert R, Rivera G, Hagnauer W (2002) Modification of vegetative phenology in a tropical semideciduous forest by abnormal drought and rain. Biotrop. 34:381-393.

Borchert R, Renner SS, Calle Z, Navarrete D, Tye A, Gautier L, Spichiger R, von Hildebrand P. 2005. Photoperiodic induction of synchronous flowering near the Equator. Nature 433:627-629.

Calle Z, Strahler AH, Borchert R (2009) Declining insolation induces synchronous flowering of Montanoa and Simsia (Asteraceae) between Mexico and the Equator. Trees 23: 1247-1254.

Choat B, Ball MC, Luly JG, Donnely CF, Holtum JAM. 2006. Seasonal patterns of leaf gas exchange and water relations in dry rain forest trees of contrasting leaf phenology. Tree Physiol. 26:657-664.

Damstra KSJ, Richardson S, Reeler B (1996) Synchronized fruiting between trees of Ficus thonningii in seasonally dry habitats. J. Biogeogr. 23:495-500.

Gutiérrez-Soto MV, Pacheco A, Holbrook NM (2008) Leaf age and the timing of leaf abscission in two tropical dry forest trees. Trees 22:393-401.

Herrera A, Ballestrini C, Tezara W (2008) Nocturnal sap flow in the $\mathrm{C}_{3}$-CAM species, Clusia minor. Trees 22: 491-497.

Janzen DH (1979) How to be a fig. Ann. Rev. Ecol Syst. 10:13-51.

Jones HG (1983) Plants and Microclimate. Cambridge University Press, Cambridge.

Lüttge U, Hertel B (2009) Diurnal and annual rhythms in trees. Trees 23:683700.

Milton K (1991) Leaf change and fruit production in six Neotropical Moraceae species. J. Ecol. 79:1-26.

Munné-Bosch S, Alegre L (2004) Die and let live: leaf senescence contributes to plant survival under drought stress. Funct. Plant Biol. 31:203-216.

Pereira RAS, Rodrigues E, de Oliveira Menezes Jr A (2007) Phenologica patterns of Ficus citrifolia (Moraceae) in a seasonal humid-subtropical region in Southern Brazil. Plant Ecol. 188:265-275.

Reich PB, Borchert R (1984) Water stress and tree phenology in a tropical dry forest in the lowlands of Costa Rica. J. Ecol. 72:61-74.

Reich PB, Borchert R (1988) Changes with leaf age in stomatal function and water status of several tropical tree species. Biotrop. 20:60-69.

Renner SS (2007) Synchronous flowering linked to changes in solar radiation intensity. New Phytol. 175:195-197.

Rivera G, Borchert R (2001) Induction of flowering in tropical trees by a 30min reduction in photoperiod: evidence from field observations and herbarium collections. Tree Physiol. 21:201-212. 
Rojas-Jiménez K, Holbrook NM, Gutiérrez-Soto MV (2007) Dry-season leaf flushing of Enterolobium cyclocarpum (ear-pod tree): above- and belowground phenology and water relations. Tree Physiol. 27:1561-1568.

Spencer H, Weiblen G, Flick B (1996) Phenology of Ficus variegata in a seasonal tropical forest at Cape Tribulation, Australia. J. Biogeogr. 23:467475 .

Valdez-Hernández M, Andrade JL, Jackson PC, Rebolledo-Vieyra M (2010) Phenology of five tree species of a tropical dry forest in Yucatan, Mexico: effects of environmental and physiological factors. Plant Soil 329:155-171.

van Schaik CP, Terborgh JW, Wright SJ (1993) The phenology of tropical forests: adaptive significance and consequences for primary consumers. Annu. Rev. Ecol. System. 24:353-377.
Windsor M, Morrison DW, Estribi MA, de Leon B (1989) Phenology of fruit and leaf production by 'strangler' figs on Barro Colorado Island, Panamá. Cell Mol. Life Sci. 43:647-653.

Yeang H-Y (2007) Synchronous flowering of the rubber tree (Hevea brasiliensis) induced by high solar radiation intensity. New Phytol. 175:283289.

Zhang G, Song Q, Yang D (2006) Phenology of Ficus racemosa in Xishuangbanna, southwest China. Biotropica 38:334-341. 